\title{
An orthodontic perspective on Larsen syndrome
}

\author{
Madoka Yasunaga ${ }^{1 *} \mathbb{0}$, Hiroyuki Ishikawa ${ }^{2}$, Kenichi Yanagita ${ }^{3}$ and Sachio Tamaoki ${ }^{1}$
}

\begin{abstract}
Background: Larsen syndrome (LS) is a rare disorder of osteochondrodysplasia. In addition to large-joint dislocations, craniofacial anomalies are typical characteristics. In this report, we performed orthodontic analyses, including skeletal and occlusal evaluations, to examine whether the craniofacial skeletal morphology leads to the craniofacial anomalies in LS.

Case presentation: A 5 year old Japanese girl who was clinically diagnosed with LS was referred to the orthodontic clinic in the Fukuoka Dental College Medical and Dental Hospital because of a malocclusion. Clinical findings at birth were knee-joint dislocations, equinovarus foot deformities, and cleft soft palate. The patient showed craniofacial anomalies with hypertelorism, prominent forehead, depressed nasal bridge, and flattened midface. To evaluate the craniofacial skeletal morphology, cephalometric analysis was performed. In the frontal cephalometric analysis, the larger widths between bilateral points of the orbitale were related to hypertelorism. The lateral cephalometric analysis revealed the midface hypoplasia and the retrognathic mandible. These findings were responsible for the flattened appearance of the patient's face, even if the anteroposterior position of the nasion was normal. Her forehead looked prominent in relation to the face probably because of the retrognathic maxilla and mandible. Both the study model and the frontal cephalometric analysis indicated constriction of the upper and lower dental arches. The posterior crossbite facilitated by the premature contacts had developed in association with the constriction of the upper dental arch.
\end{abstract}

Conclusions: This patient had some craniofacial anomalies with characteristic appearances in LS. It was evident that the underlying skeletal morphology led to the craniofacial dysmorphism.

Keywords: Larsen syndrome, Skeletal morphology, Craniofacial anomalies, Cephalometric analysis

\section{Background}

Larsen syndrome (LS) was first described by Loren J. Larsen in 1950. It is a very rare genetic or nongenetic (sporadic) osteochondrodysplasia [1]. LS affects approximately one in 100,000 newborn children each year [2]. LS is clinically represented by various features showing multiple congenital dislocations of the hip, knee, and elbow joints, equinovarus, or equinovalgus foot deformities,

\footnotetext{
*Correspondence: madoka@college.fdcnet.ac.jp

1 Section of Orthodontics, Department of Oral Growth and Development,

Fukuoka Dental College, 2-15-1 Tamura, Sawara-ku, Fukuoka 8140193,

Japan

Full list of author information is available at the end of the article
}

cylindrically shaped fingers, spinal anomalies-including scoliosis and cervical kyphosis-hearing loss caused by malformations of the ear ossicles, and characteristic craniofacial abnormalities [1,3-5]. The diagnosis of LS is based on these clinical findings [6]. LS is genetically heterogeneous, and consists of autosomal recessive or autosomal dominant disorders caused by respective mutations in the CHST3, B4GALT7, and GZF1 genes [7], or in the $F L N B$ gene [8-11]. Genetic testing of the presence of mutations in these genes provides a useful adjunct to the diagnosis of LS patients with atypical or milder clinical manifestations $[9,10,12]$. The prognosis in the autosomal dominant form is relatively favorable 
than that in the recessive form if patients are treated with orthopedic surgery, physical therapy, fixation in plaster, or procedures used to treat the various symptoms associated with LS. However, in the autosomal recessive form, the clinical phenotype is associated with a higher mortality than the autosomal dominant form [9]. Intelligence in individuals with LS is usually unaffected [10].

Cleft palate was also reported in $23-50 \%$ of LS patients $[6,13,14]$. Characteristic facial features considered as craniofacial anomalies include a prominent forehead (frontal bossing), flattening of the bridge of the nose (depressed nasal bridge), wide-set eyes (ocular hypertelorism), and flattened midface (midface hypoplasia) [1, $3-5,15-20]$. However, the relationship between the craniofacial skeleton and facial anomalies is unclear because there are only a few reports related to the evaluation of the craniofacial skeleton in LS [15-17]. In addition to these anomalies, some reports have also referred to the presence of dental anomalies in LS, such as hypodontia, supernumerary teeth, microdontia, and malocclusions [15-20], but dental disturbances remain controversial.

In this report, we presented a Japanese girl diagnosed with LS and examined whether craniofacial skeletal and dental arch morphology lead to craniofacial anomalies and dental disturbances based on the orthodontic examinations.

\section{Case presentation}

A 5 year old Japanese girl who had previously been diagnosed with LS was referred to the orthodontic clinic in the Fukuoka Dental College Medical and Dental Hospital in Fukuoka, Japan, because she had posterior crossbite. She is the second child with healthy parents who have no family history of genetic disorders. The diagnosis of LS was based on clinical findings. At birth, she had knee joint dislocations, equinovarus foot deformities, and a cleft of the soft palate only with no extension to the hard palate, alveolus, or lip (type 1 of Veau's classification [21]). Operations for dislocations and equinovarus deformities were respectively performed at the ages of 4 and 9 months. Furlow's palatoplasty was performed for the soft palate repair when she was 1.7 years old. She had not undergone any orthodontic treatment including presurgical orthodontics. The Enjoji scale [22], recorded at the age of four, revealed delays of social behavior and emotional and language development.

She underwent orthodontic examinations, including general, facial and intraoral examinations, lateral and frontal cephalometric analyses, and a study model examination for orthodontic diagnosis. On general examination, her height and weight were $112.3 \mathrm{~cm}$ and $15.1 \mathrm{~kg}$, respectively. These were below the reference for the 75th and 10th percentile in her age and sex group, respectively.
The hand-wrist radiograph was used to examine her skeletal maturity (Fig. 1a). The patient's skeletal age was matched at 5.3 years by the TW2 RUS method applied to the Japanese population, whereas the GreulichPyle Atlas method estimated the corresponding age at 5.5 years [23]. Based on these methods, her skeletal age almost matched her chronological age of 5.6 years. She had long cylindrically shaped fingers (Fig. 1b). Dysmorphic facial features were noted, including hypertelorism, a prominent forehead, depressed nasal bridge, and a flattened midface. Her facial profile was straight. Her chin point deviated toward the right side from the facial midline (Fig. 2).

Intraoral examination revealed the complete primary dentition with an overjet of $2.0 \mathrm{~mm}$, an overbite of $2.0 \mathrm{~mm}$, and mesial step-type terminal planes on both sides. There were no spaces around the fused tooth with the left deciduous central and lateral incisors in the upper dentition, while the lower dentition exhibited anterior crowding and mesial rotation of the first deciduous molars on both sides. On the right side, posterior crossbite was observed resulting from a functional lateral shift of the mandible owing to the premature contacts between the maxillary and mandibular right primary molars. In centric relation prior to the mandibular shifting, the

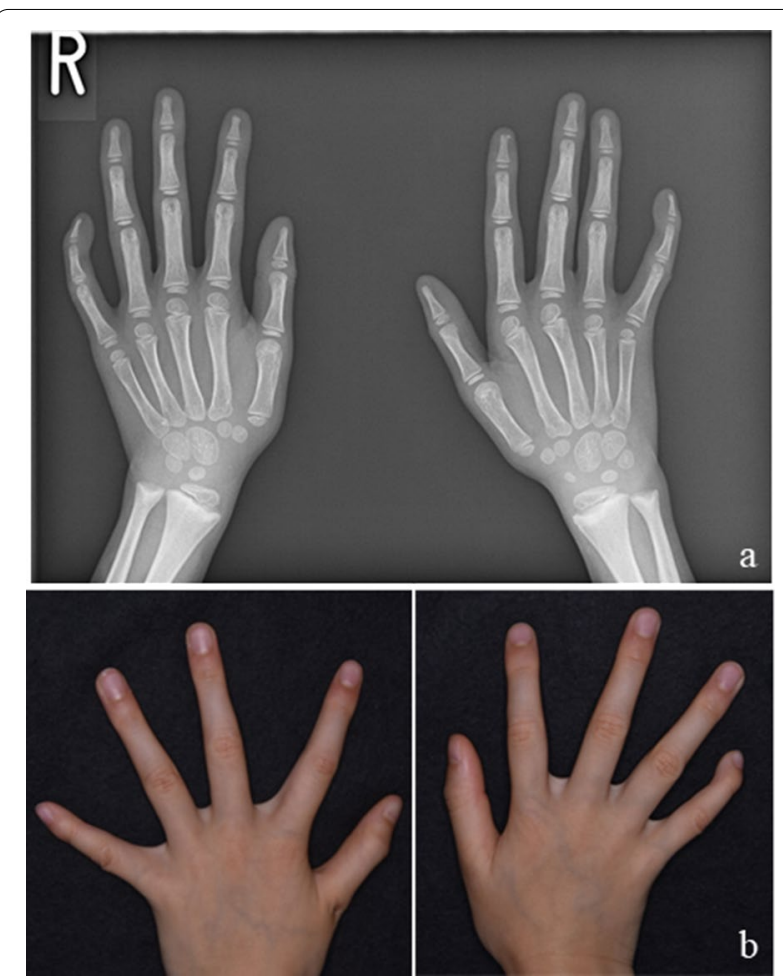

Fig. 1 A hand-wrist radiograph and a photo of hands of the patient. a A hand-wrist radiograph was used to evaluate the skeletal age. $\mathbf{b}$ Cylindrically shaped fingers 

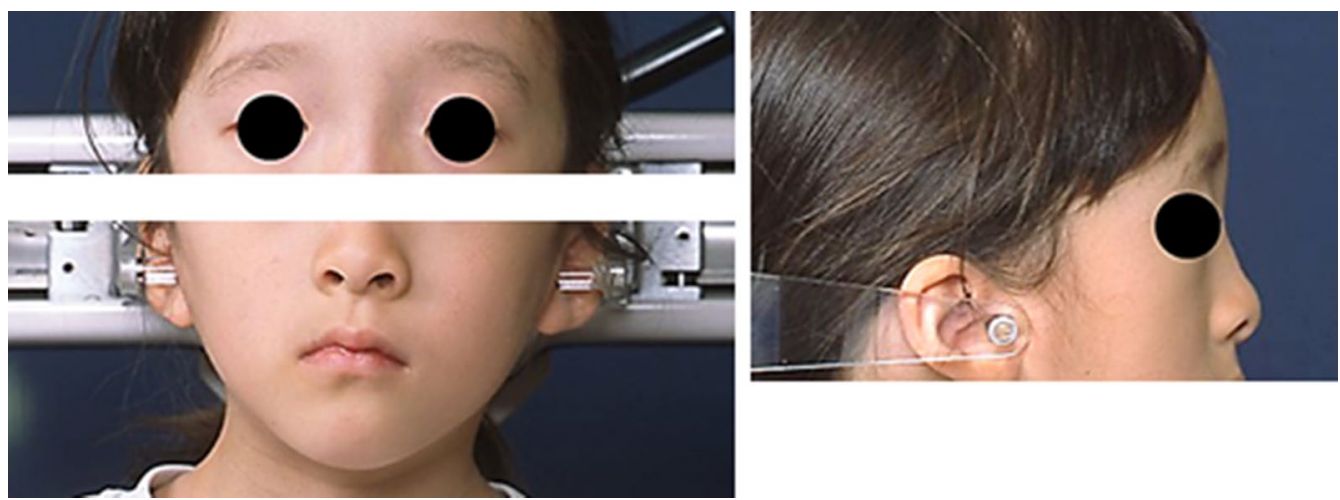

Fig. 2 Facial photos of the studied patient showing hypertelorism, a prominent forehead, depressed nasal bridge, and a flat face

mandibular dental midline was nearly consistent with the facial midline. In centric occlusion, the maxillary and mandibular dental midlines deviated $1.5 \mathrm{~mm}$ to the left and $2.0 \mathrm{~mm}$ to the right relative to the facial midline, respectively. As a result, the upper and lower dental midline discrepancy was $3.5 \mathrm{~mm}$ (Fig. 3).

On study models examination, the arch widths between the primary canines, and the first and second molars were measured to compare them with the standard values obtained from Japanese children with normal primary occlusions (Fig. 4 and Table 1) [24]. In the case of the primary canine, all the distances of the bilateral tips and the bilateral palatal or lingual cervical lines were measured. In the cases of the primary molars, the distances between the bilateral buccal grooves of the first and second molars were also measured. On the maxillary and mandibular dentitions, all the arch width measurements were significantly smaller than one standard deviation (SD) below the Japanese norms matched for the patient's age.

The panoramic radiograph showed that the maxillary left lateral incisor was congenitally missing. The tooth germ of the maxillary left second molar was not present. The tooth crown of the unerupted, maxillary right central incisor was rotated and was close to that of the maxillary right lateral incisor. The fused tooth with the left deciduous central and lateral incisors showed the union of tooth crowns by the dentin and two roots with independent root canals (Fig. 5).

Figure 6 shows the lateral and frontal cephalogram of the patient. Cephalograms were taken in a standard

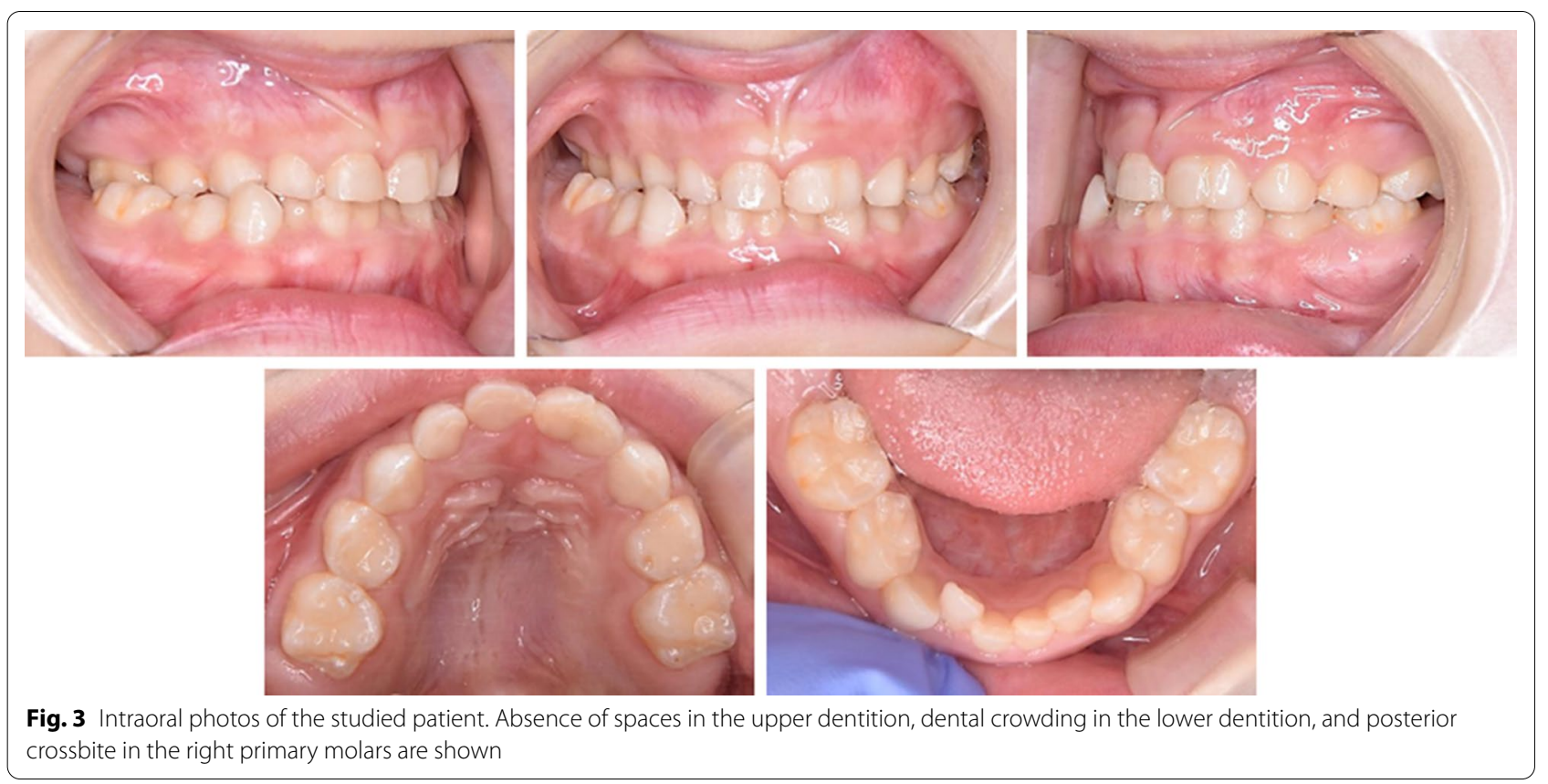




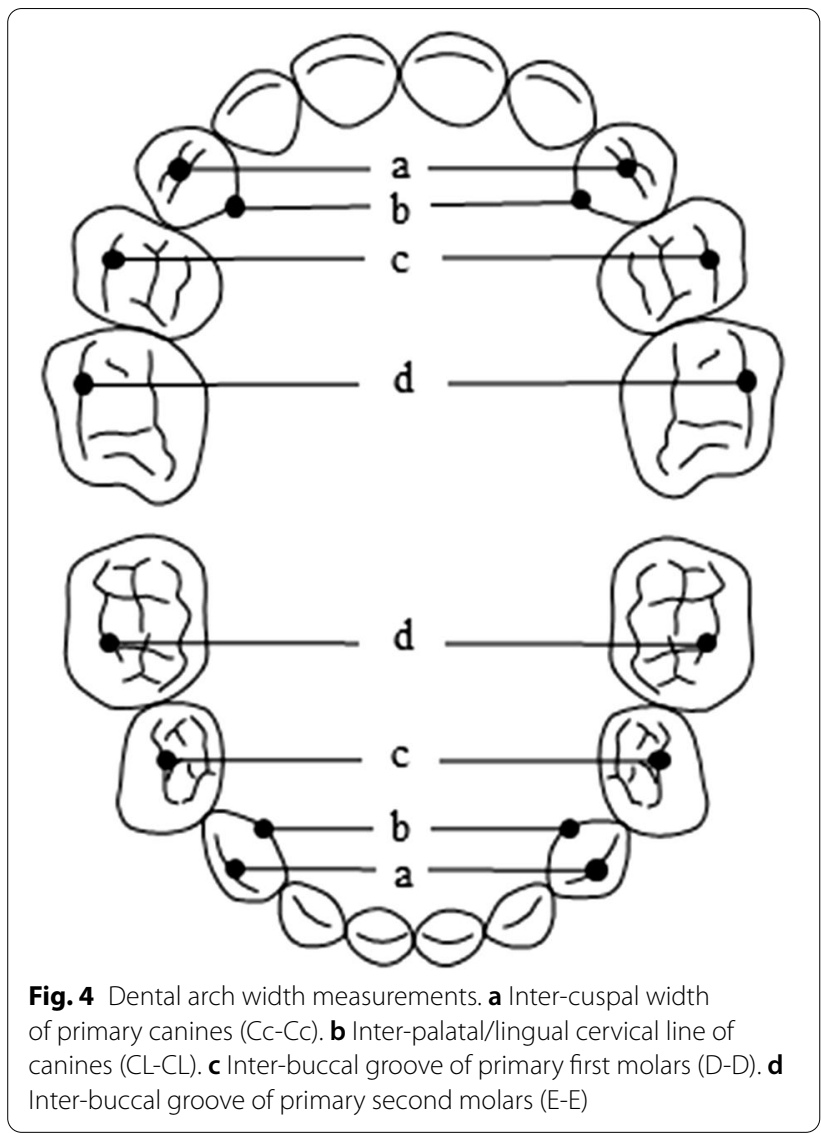

Table 1 Study model examination

\begin{tabular}{llll}
\hline Measurements & Present case & \multicolumn{2}{l}{$\begin{array}{l}\text { Japanese children* } \\
{[24]}\end{array}$} \\
\cline { 3 - 4 } & & Mean & SD \\
\hline Maxilla & & & \\
Cc-CC & 23.6 & 30.73 & 1.71 \\
$C_{\mathrm{L}-C}-\mathrm{L}$ & 17.5 & 25.48 & 1.65 \\
D-D & 32.6 & 39.85 & 1.68 \\
E-E & 37.5 & 46.10 & 1.77 \\
Mandible & & & \\
Cc-CC & 19.0 & 23.84 & 1.34 \\
C $-C_{L}$ & 14.5 & 19.55 & 1.40 \\
D-D & 24.0 & 33.48 & 1.73 \\
E-E & 32.0 & 38.62 & 1.51 \\
\hline
\end{tabular}

Dental arch width measurements are in millimeters

*The means and SDs were given as mixed sex values for $\mathrm{Cc}-\mathrm{Cc}, \mathrm{CL}-\mathrm{CL}$, and D-D, whereas those were given as girl's values for $\mathrm{E}-\mathrm{E}$.

manner with a magnification ratio of 1.1. Figure $7 \mathrm{a}, \mathrm{b}$ shows the conventional cephalometric analyses. The results are given in Table 2 . These indicated the posteriorly positioned maxilla and mandible (SNA, SNB, and

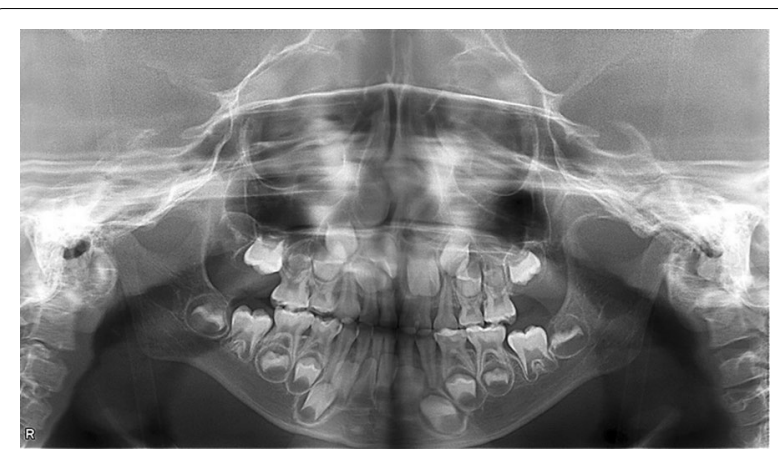

Fig. 5 Panoramic radiograph showing the absence of the maxillary left second molar and lateral incisor

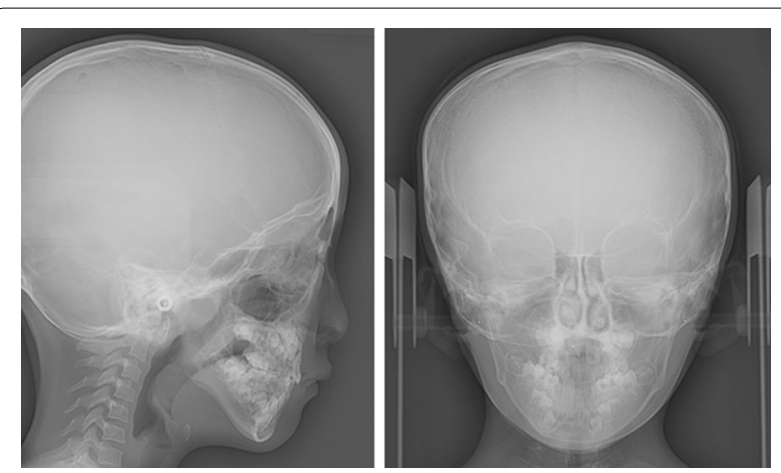

Fig. 6 The lateral and frontal cephalograms

facial angle), skeletal Class III jaw relationship (ANB), steep mandibular plane (FMA) with the large Gonial angle, and growth tendency of the mandible (Y-axis) toward the postero-inferior direction. Inclination of the maxillary primary incisors was within the normal range (U1 to $\mathrm{SN}$ ), while the mandibular primary incisor inclined more lingually than the norm (L1 to Mandible) [25].

Figure 7c shows the facial depth measurements used in this study. The horizontal positions of the six landmarks in relation to a line perpendicular to the $\mathrm{S}-\mathrm{N}$ line that passed through sella, were measured based on the method proposed by Ono [26]. The results of the facial depth measurements were shown in Table 2. The depths measured on Or, PTM, Pog, Me, and Ar were smaller than one SD below the Japanese norms matched for the patient's age and sex, while the depth of the nasion was within the normal range [26]. For the posterior part of the mandible, the facial depths measured on Go were close to one SD below the norms. These indicated that the orbitale, the maxilla, and mandible were positioned posteriorly relative to the anterior cranial base.

The frontal cephalometric analysis was performed as shown in Fig. 8. The facial midline was drawn through 

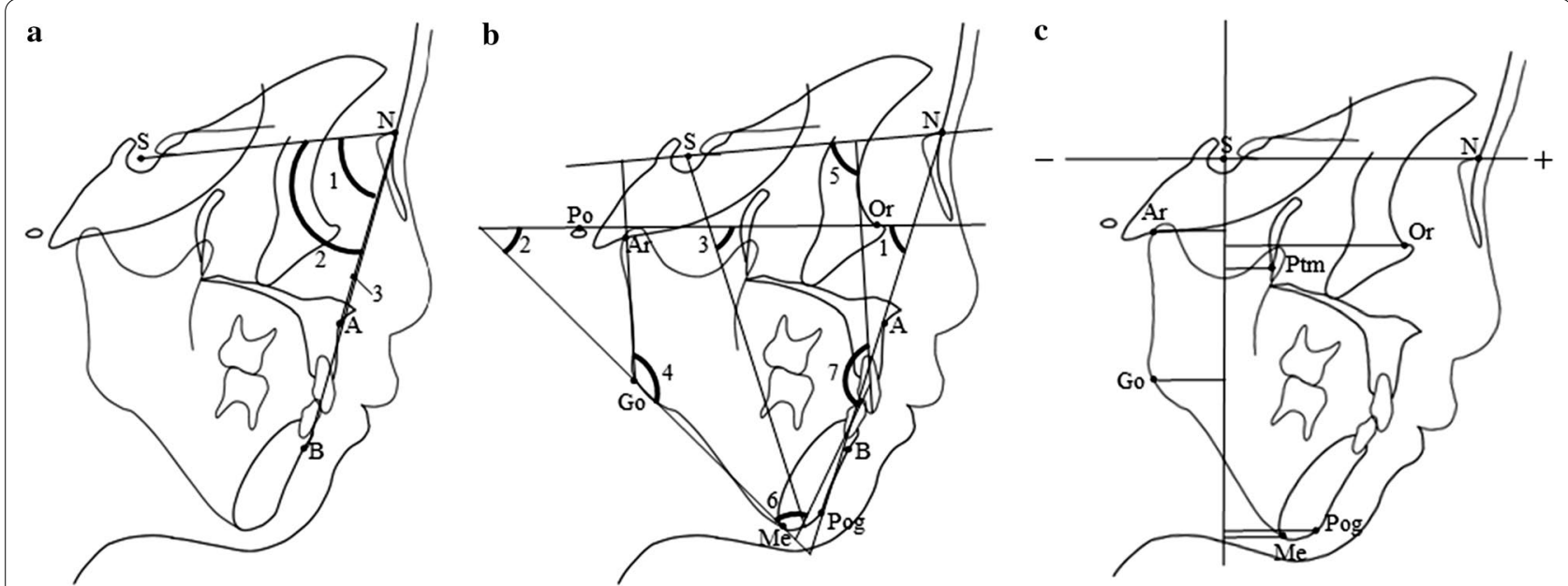

Fig. 7 Lateral cephalometric landmarks and measurements. a (1) SNA, (2) SNB, and (3) ANB. b (1) Facial angle, (2) Frankfort-mandibular plane angle (FMA), (3) Y-axis, (4) Gonial angle, (5) U1 to SN, (6) L1 to mandibular plane angle (L1 to Mp), (7) Interincisal angle (S, sella; N, nasion; A, point A; B, point B; Po, porion; Or, orbitale; Go, gonion; Pog, pogonion; Me, menton and $\mathrm{Ar}$, articulare). c. Facial depth representation ( $S$, sella; $N$, nasion; Or, orbitale; Ptm, pterygomaxillary fissure; Pog, pogonion; Me, menton; Go, gonion and Ar, articulare)

Table 2 Lateral cephalometric analysis

\begin{tabular}{lrrr}
\hline & Present case & \multicolumn{2}{c}{$\begin{array}{c}\text { Japanese girl } \\
{[25,26]}\end{array}$} \\
\cline { 3 - 4 } & & Mean & SD \\
\hline Angular measurement (in degrees) & & & \\
SNA & 68.5 & 80.09 & 3.43 \\
SNB & 68.0 & 76.04 & 3.47 \\
ANB & +0.5 & +4.67 & 1.73 \\
Facial angle & 71.0 & 84.50 & 3.24 \\
FMA & 44.5 & 29.50 & 3.40 \\
Y-axis & 74.0 & 61.51 & 3.39 \\
Gonial angle & 139.0 & 129.95 & 5.26 \\
U1 to SN & 89.0 & 87.19 & 6.51 \\
L1 to Mp & 68.0 & 85.71 & 4.11 \\
Interincisal angle & 150.0 & 148.40 & 9.50 \\
Facial depth measurement (in millimeters) & & & \\
N & 63.0 & 62.0 & 2.43 \\
Or & 43.5 & 51.1 & 2.66 \\
Ptm & 11.5 & 14.8 & 2.63 \\
Pog & 23.5 & 38.3 & 5.67 \\
Me & 14.5 & 30.2 & 5.53 \\
Go & -17.5 & -14.0 & 3.62 \\
Ar & -18.0 & -15.7 & 2.21 \\
\hline
\end{tabular}

the Crista Galli and perpendicular to the line that passed through the latero-orbitale (Lo) bilaterally. For each of the 14 landmarks used, the distance to the facial midline was measured on both sides. The facial widths were obtained based on the addition of the bilateral distances measured on each landmark [26]. Table 3 shows the results of the

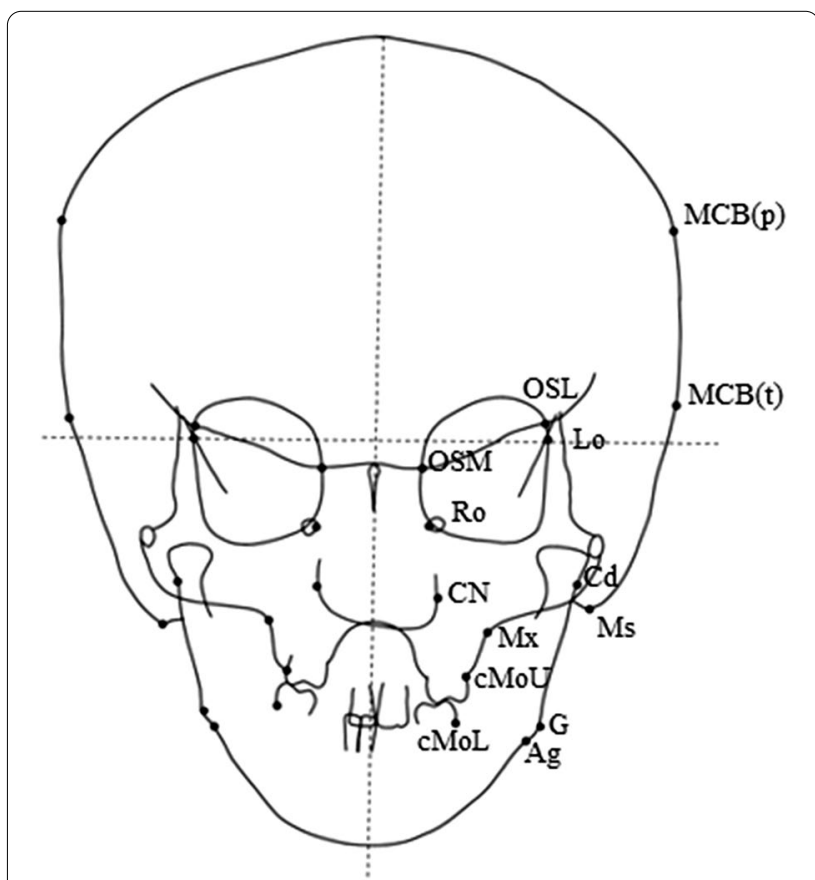

Fig. 8 Frontal cephalometric landmarks and measurements (MCB(p), maximum cranial breadth (parietal bone); $\mathrm{MCB}(\mathrm{t})$, maximum cranial breadth (temporal bone); Lo, latero-orbitale; OSM, cross-point between anterior cranial fossa and orbital outlines; OSL, cross-point between the superior margin of the lesser wing of the sphenoid bone and orbital outline; Ro, foramen rotundum; CN, outmost point on the nasal cavity outline; Ms, mastoidale; $\mathrm{Mx}$, maxillare; $\mathrm{CMoU}$, cervical line of primary molars on the maxilla; $C M o L$, cervical line of primary molars on the mandible; $\mathrm{Cd}$, condylion; Go, gonion and Ag, antegonial notch) 
Table 3 Frontal cephalometric facial width measurements

\begin{tabular}{llll}
\hline Measurement & Present case & \multicolumn{2}{c}{ Japanese girl [26] } \\
\cline { 3 - 4 } & & Mean & SD \\
\hline MCB(p) & 155.0 & 144.5 & 7.84 \\
MCB $(\mathrm{t})$ & 152.5 & 150.7 & 6.65 \\
Lo & 88.5 & 84.8 & 3.33 \\
OSM & 25.0 & 21.5 & 1.89 \\
OSL & 89.5 & 79.1 & 3.61 \\
Ro & 27.5 & 30.7 & 3.42 \\
CN & 30.0 & 26.7 & 1.72 \\
Ms & 107.0 & 103.0 & 5.66 \\
Mx & 55.0 & 62.0 & 2.60 \\
CMoU & 45.0 & 50.9 & 2.20 \\
CMoL & 45.5 & 48.2 & 2.20 \\
Cd & 101.0 & 99.0 & 5.06 \\
Go & 84.5 & 83.5 & 4.19 \\
Ag & 79.0 & 76.6 & 3.90 \\
\hline
\end{tabular}

Facial width measurements are in millimeters

facial width measurements. Compared with the Japanese norms matched for the patient's age and sex, the cranial width measurements taken at MCB(p), Lo, OSM, OSL, and $\mathrm{CN}$ yielded values that exceeded the Japanese norms by one SD. The widths measured on the $\mathrm{Mx}, \mathrm{cMoU}$, and cMoL, were smaller than those of the Japanese norms, and indicated narrow maxillary basal arch and maxillary and mandibular dental arch widths.

Based on the examinations performed, an orthodontic diagnosis of unilateral posterior crossbite due to a functional lateral shift of the mandible, a skeletal Class III jaw relationship, narrow maxillary and mandibular dental arches, mandibular anterior mild crowding, and congenital missing of the maxillary left lateral incisor and the maxillary left second molar was made. The proposed treatment plan included (1) the maxillary dental arch expansion to eliminate the premature contacts between the maxillary and mandibular right primary molars and to improve the lateral shift of the mandible, (2) observation of the jaw growth and occlusal development with potential options of the maxillary protraction and the mandibular dental arch expansion, and (3) a fixed appliance treatment for the permanent dentition. We initiated the treatment with the use of the removable expansion plate for the maxillary dental arch expansion. No obvious problems have been observed in treatment response of the patient so far.

\section{Discussion and conclusions}

In this case, we performed cephalometric analyses to examine how the craniofacial anomalies were linked to craniofacial skeletal morphologies. The frontal cephalometric analysis exhibited skeletal characteristics that related to hypertelorism, and yielded increased widths measured at OSM, OSL, and Lo, compared with the Japanese norms. Larger widths measured between bilateral points of the orbitale were directly linked to the broadly spaced eyes.

The lateral cephalometric analysis revealed the midface hypoplasia and the retrognathic mandible. Several studies have attempted to assess the significance of the flat face or the posterior position of the maxilla in LS with lateral cephalometric analyses [15-17]. Some reports noted that the SNA angles of LS patients were smaller than those of the norms. These findings are indicative that the maxilla was posteriorly positioned. For the mandible, there are studies that yielded smaller SNB angles compared with the norms [15-17]. The cephalometric analysis in this study showed that both the SNA and SNB angles were significantly smaller than those of Japanese girls. The facial depth measurements revealed the posterior positions of Or, Pog, and Me. These findings indicated that the orbital area, the maxilla, and the mandible were located posteriorly relative to the anterior cranial base. The skeletal features appear to result in a flat face that is one of typical facial anomalies in LS. Even though the anteroposterior position of the nasion was normal, her forehead looked prominent relative to the face, probably owing to the posterior position of the midface and the mandible. The cephalometric analyses provided new details on the relations of the craniofacial appearances and the skeletal morphology in LS.

Table 4 summarizes the oral findings in case reports of LS [15-20]. In this case, dental abnormalities contain hypodontia and contracted dental arches. The maxillary left second molar and the lateral incisor seemed to be congenitally missing in this case. Some reports revealed that the prevalence of the maxillary lateral incisor hypodontia was higher in patients with cleft palate compared with the non-cleft population [27]. In the present case, the congenitally missing teeth of the maxillary lateral incisor may be related to the cleft palate. However, the association of the second molar hypodontia with the cleft palate is unclear. The frequency of hypodontia (in the absence of any disorders) was reported to range from $1.6 \%$ and $10.09 \%$ [28, 29], while four out of 19 LS individuals including the present case and 18 cases in previous reports [1, 10, 15-19] had missing teeth attributed to congenital etiologies. Whether this is a typical dental symptom in LS is still debated. Despite the fact that the mechanisms responsible for the missing teeth remain unclear, some of the factors that facilitate osteochondrodysplasia may be related to the impairment of the tooth germs and may disrupt tooth formation [30]. The patient exhibited 
Table 4 Summary of information of oral findings in seven cases of Larsen syndrome presented in this study and in previous reports [15-20]

\begin{tabular}{|c|c|c|c|c|c|c|c|}
\hline & Tsang et al. [15] & Chien et al. [18] & $\begin{array}{l}\text { Kawahara et al. } \\
\text { [16] }\end{array}$ & Percin et al. [19] & Kozaki et al. [20] & Sajnani et al. [17] & Present case \\
\hline Age & 15 & 29 & 8 & 14 & 8 & 8 & 5 \\
\hline Sex & Female & Female & Male & Female & Female & Male & Female \\
\hline $\begin{array}{l}\text { Number of } \\
\text { abnormal teeth }\end{array}$ & $11 \mathrm{CMT}$ & None & $4 \mathrm{CMT}$ & $2 \mathrm{CST}$ & ND & $2 \mathrm{CMT}$ & $2 \mathrm{CMT}$ \\
\hline $\begin{array}{l}\text { Cleft lip and/or } \\
\text { palate }\end{array}$ & $\begin{array}{l}\text { Cleft left lip and } \\
\text { palate }\end{array}$ & ND & Cleft palate & Cleft palate & Cleft soft palate & None & Cleft soft palate \\
\hline $\begin{array}{l}\text { Incisor relation- } \\
\text { ship }\end{array}$ & $\begin{array}{l}\text { O.J.: }-6 \mathrm{~mm} \\
\text { anterior crossbite }\end{array}$ & ND & $\begin{array}{l}\text { O.J.: }-2 \mathrm{~mm} \\
\text { O.B.: }+5 \mathrm{~mm} \\
\text { anterior crossbite }\end{array}$ & ND & $\begin{array}{l}\text { Edge-to-edge } \\
\text { bite }\end{array}$ & $\begin{array}{l}\text { Anterior open } \\
\text { bite }\end{array}$ & $\begin{array}{l}\text { O.J.: }+2 \mathrm{~mm} \\
\text { O.B.: }+2 \mathrm{~mm}\end{array}$ \\
\hline $\begin{array}{l}\text { Posterior cross } \\
\text { bite }\end{array}$ & Unilateral: left & Found* & Bilateral & ND & Unilateral: right & Bilateral & Unilateral: right \\
\hline
\end{tabular}

CMT congenital missing teeth, CST congenital supernumerary teeth, O.J. overjet, O.B. overbite, ND no description

*Posterior cross bite with no description as to whether unilateral or bilateral

an overjet of $2.0 \mathrm{~mm}$ and an overbite of $2.0 \mathrm{~mm}$, while previous studies reported a variety of overjet and overbite findings in LS. Constricted upper and lower dental arches were observed as the outcomes of the study model and frontal cephalometric analysis, leading to the absence of spaces in the upper dentition and to a dental crowding in the lower dentition. Furthermore, posterior crossbite in the right primary molars facilitated by premature contacts were associated with constricted upper dental arches. Previous reports revealed two cases of unilateral and two cases of bilateral posterior crossbites as well as one case with undetermined bite sites. However, no prior reports described the interactions between the posterior crossbites and contracted dental arches. This patient underwent an operation of the soft palate cleft when she was 1.7 years old. The incident rate of cleft palate in LS ranges between 23 and $50 \%[6,13,14]$. In cleft palate patients, the contracted maxillary dental arch was related to the underdevelopment of the maxilla owing to the postsurgical scar tissue formation on the palates [31]. Given that the operative method used in this patient was the Furlow palatoplasty without periosteal detachment, the formed scar was considered to be small [31, 32]. In addition, the cleft was limited to the soft palate. A weak relationship may exist between the contracted maxillary dental arch and the cleft palate in this case. Considering that several case reports showed posterior crossbites [15$18,20]$ or a high-arched palate [33] in LS, maxillary dental arch constrictions can often occur in LS, irrespective of whether it induces premature contacts or not. As shown in this case, the lateral shift of the mandible resulted from the premature contacts that caused deviation of the chin point, and may have facilitated the formation of facial asymmetries during growth.

This case report revealed that the underlying craniofacial skeletal morphology leads to the craniofacial dysmorphism in LS.

\section{Abbreviation \\ LS: Larsen syndrome.}

\section{Acknowledgements}

We are deeply grateful to the patient's family for providing medical records and medical images for this case report and to the clinicians for their contributions to our study. We would like to acknowledge Enago (www.enago.jp) for the English language review.

\section{Authors' contributions}

MY designed the study, collected and analyzed the data, and wrote, revised and supervised the manuscript. HI discussed the data, and wrote, revised and supervised the manuscript. KY collected the clinical data. ST supervised the manuscript. All authors read and approved the final manuscript.

\section{Funding}

This work was supported by JSPS KAKENHI (Grant Numbers: 19K24158 and $20 K 18771$ to Madoka Yasunaga). The funders played no role in the design of the study, analysis and interpretation of the data or the writing of the manuscript.

\section{Availability of data and materials}

All data generated or analyzed during this study are included in this published article.

\section{Ethical approval and consent to participate}

Ethical approval not applicable. The patient's mother provided written informed consent to participate in this case report.

\section{Consent for publication}

Written consent for publication was obtained from the participant's mother. A copy of the written consent is available for review by the editor of this journal.

\section{Competing interests}

The authors declare that they have no competing interests. 


\section{Author details}

1 Section of Orthodontics, Department of Oral Growth and Development, Fukuoka Dental College, 2-15-1 Tamura, Sawara-ku, Fukuoka 8140193, Japan. ${ }^{2}$ Executive Trustee, Educational Institution, Fukuoka Gakuen, 2-15-1 Tamura, Sawara-ku, Fukuoka 8140193, Japan. ${ }^{3}$ Pediatric Dentistry, Fukuoka Children's Hospital, 5-1-1 Kashiiteriha, Higashi-ku, Fukuoka 8130017, Japan.

Received: 29 September 2020 Accepted: 22 February 2021

Published online: 10 March 2021

\section{References}

1. Larsen LJ, Schottstaedt ER, Bost FC. Multiple congenital dislocations associated with characteristic facial abnormality. J Pediatr. 1950;37:574-81.

2. Bonaventure J, Lasselin C, Mellier J, Cohen-Solal L, Maroteaux P. Linkage studies of four fibrillar collagen genes in three pedigrees with Larsen-like syndrome. J Med Genet. 1992;29:465-70.

3. Laville JM, Lakermance P, Limouzy F. Larsen's syndrome: review of the literature and analysis of thirty-eight cases. J Pediatr Orthop. 1994;14:63-73.

4. Stanley CS, Thelin JW, Miles JH. Mixed hearing loss in Larsen syndrome. Clin Genet. 1988;33:395-8.

5. Marques LHS, Martins DV, Juares GL, Lorenzetti FTM, Monsanto RDC. Otologic manifestations of Larsen syndrome. Int J Pediatr Otorhinolaryngol. 2017;101:223-9.

6. Goodman RM, Gorlin RJ. Larsen syndrome. In: Atlas of the face in genetic disorders. 2rd ed. St. Louis: Mosby; 1977. p. 148-9.

7. Patel N, Shamseldin HE, Sakati N, Khan AO, Softa A, Al-Fadhli FM, et al. GZF1 mutations expand the genetic heterogeneity of Larsen syndrome. Am J Hum Genet. 2017;100:831-6.

8. Krakow D, Robertson SP, King LM, Morgan T, Sebald ET, Bertolotto C, Wachsmann-Hogiu S, Acuna D, Shapiro SS, Takafuta T, et al. Mutations in the gene encoding filamin B disrupt vertebral segmentation, joint formation and skeletogenesis. Nat Genet. 2004;36:405-10.

9. Bicknell LS, Farrington-Rock C, Shafeghati Y, Rump P, Alanay Y, Alembik Y, Al-Madani N, Firth H, Karimi-Nejad MH, Kim CA, et al. A molecular and clinical study of Larsen syndrome caused by mutations in FLNB. J Med Genet. 2007;44:89-98.

10. Girisha KM, Bidchol AM, Graul-Neumann L, Gupta A, Hehr U, Lessel D, et al. Phenotype and genotype in patients with Larsen syndrome: clinical homogeneity and allelic heterogeneity in seven patients. BMC Med Genet. 2016;17:27.

11. Risse N, Lindberg BR, Kulseth MA, Fredwall SO, Lundby R, Estensen ME, et al. Clinical diagnosis of Larsen syndrome, Stickler syndrome and LoeysDietz syndrome in a 19-years old male: a case report. BMC Med Genet. 2018;19:155.

12. Kodra N, Diamonstein C, Hauser NS. A case study of atypical Larsen syndrome with absent hallmark joint dislocations. Mol Genet Genomic Med. 2019;7:e648.

13. DeSmet L, Legius E, Fabry G, Fryns JP. The Larsen syndrome. The diagnostic contribution of the analysis of the metacarpophalangeal pattern profile. Genet Couns. 1993:4:157-64.

14. Larsen syndrome. In: Raoul CM, lan DK, Judith EA, editors. Gorlin's syndromes of the head and neck. 5rd ed. New York: Academic; 2010. p. 984-8.
15. Tsang MCK, Ling JYK, King NM, Chow SK. Oral and craniofacial morphology of a patient with Larsen syndrome. J Craniofac Genet Dev Biol. 1986;6:357-62

16. Kawahara I, Sato I, Ishii K, Hanada K. A case report of Larsen syndrome with cleft palate. J Jpn Cleft Palate Assoc. 1998;23:331-5.

17. Sajnani AK, Yiu CK, King NM. Larsen syndrome: a review of the literature and case report. Spec Care Dent. 2010;30:255-60.

18. Chien M, Punwani I, Watanabe K. Advanced periodontitis associated with Larsen's syndrome: case report. Pediatr Dent. 1995;17:62-4.

19. Percin EF, Gedik R, Develioglu H, Kunt T. Larsen's syndrome with dental anomalies: report of a case. ASDC J Dent Child. 2002;69:172-4.

20. Kozaki Y, Yoshimasu H, Sato Y, Miyazaki H, Matsumoto T, Okada S, et al. A case of Larsen syndrome with cleft palate. J Jpn Cleft Palate Assoc. 2003:28:271-6.

21. Veau V. Division palatine. Paris: Masson; 1931

22. Motegi M, Inagaki A, Minakata T, Sekiya S, Takahashi M, Sekiya Y, et al. Developmental delays assessed using the Enjoji scale in children with cochlear implants who have intellectual disability with or without autism spectrum disorder. Auris Nasus Larynx. 2019;46:498-506.

23. Tanaka T, Sato M, Murata M, Anzou S, Takai S. TW2 bone age for Japanese children. In: The Japanese Association for Human Auxology and The Japanese Society for Pediatric Endocrinology, editors. Tokyo: Medical Review Company Limited; 2018.

24. Ono $H$, Ochiai $S$, Sato $H$. Study on growth changes of dentition (1) growth changes of deciduous dentition. J Jpn Stomatol Soc. 1960;27:361-7.

25. lizuka T. A study of facial growth in Japanese children using lateral cephalograms. J Jpn Stomatol Soc. 1958;25:260-72.

26. Japanese Society of Pediatric Dentistry. A study on the cephalometric standards of Japanese children. J Jpn Pediatr Dent. 1995:33:659-96.

27. Shapira Y, Lubit E, Kuftinec MM. Hypodontia in children with various types of clefts. Angle Orthod. 2000;70:16-21.

28. Bahreman A. Orthodontic management of hypodontia. In: Bahreman A, editor. Early-age orthodontic treatment. Chicago: Quintessence; 2013. p. 157-88.

29. Yamasaki Y, Iwasaki T, Hayashi H, Saitoh I, Tokutomi J, Yawaka Y, et al. Frequency of congenitally missing permanent teeth in Japanese children. J Jp Pediatr Dent. 2010;48:29-39.

30. Karlstedt E, Kaitila I, Pirinen S. Phenotypic features of dentition in diastrophic dysplasia. J Craniofac Genet Dev Biol. 1996;16:164-73.

31. Losee JE, Kirschner RE. Comprehensive cleft care. 2nd ed. Boca Raton: CRC Press; 2016.

32. LaRossa D, Jacson OH, Kirschner RE, Low DW, Solot CB, Cohen MA, et al. The children's hospital of Philadelphia modification the Furlow doubleopposing z-palatoplasty: Iong-term speech and growth results. Clin Plast Surg. 2004;31:243-9.

33. Petrella R, Rabinowitz JG, Steinmann B, Hirschhorn K. Long-term followup of two sibs with Larsen syndrome possibly due to parental germ-line mosaicism. Am J Med Genet. 1993;47:187-97.

\section{Publisher's Note}

Springer Nature remains neutral with regard to jurisdictional claims in published maps and institutional affiliations.

Ready to submit your research? Choose BMC and benefit from:

- fast, convenient online submission

- thorough peer review by experienced researchers in your field

- rapid publication on acceptance

- support for research data, including large and complex data types

- gold Open Access which fosters wider collaboration and increased citations

- maximum visibility for your research: over 100M website views per year

At BMC, research is always in progress.

Learn more biomedcentral.com/submissions 